\section{A alimentação saudável na ótica dos adolescentes: percepções e barreiras à sua implementação e características esperadas em materiais educativos}

\author{
Healthy eating according to teenagers: \\ perceptions, barriers, and expected \\ characteristics of teaching materials
}

\footnotetext{
${ }^{1}$ Coordenação Geral da Política de Alimentação e Nutrição, Ministério da Saúde, Brasília, Brasil. 2 Faculdade de Medicina, Universidade de São Paulo, São Paulo, Brasil.

3 Faculdade de Saúde Pública, Universidade de São Paulo, São Paulo, Brasil.

Correspondência N. Toral

Coordenação Geral da Política de Alimentação e Nutrição, Ministério da Saúde.

SEPN 511, Bloco C, Edifício Bittar IV, $4^{\circ}$ andar, Brasília, DF

70750-543, Brasil. natytb@usp.br
}

\begin{abstract}
The aim of this study was to evaluate perceptions, barriers, and characteristics of teaching materials to promote healthy eating, as described by teenagers. Four focus groups were conducted with 25 adolescents, including questions on: perceptions regarding diet and motivations to change; concepts of (and barriers to) healthy eating; and characteristics needed for teaching materials to promote healthy eating. The teens were often undecided when attempting to classify a diet as healthy. They generally reported feeling insecure about making dietary changes, but showed adequate notions of healthy eating. The main barriers involved personal and social characteristics: temptation, food flavors, parental influence, and lack of time and options for healthy snacks at school. According to these teenagers, educational materials for promotion of healthy eating should emphasize the immediate benefits and emphasize high-impact messages on the health risks of unhealthy diet.
\end{abstract}

Feeding Behavior; Adolescent Health; Health Promotion
Natacha Toral

Maria Aparecida Conti 2

Betzabeth Slater 3

\section{Introdução}

Apesar da crescente ampliação das reflexões teóricas e metodológicas da educação em saúde, ainda é comum a utilização de métodos e estratégias pautadas em modelos teóricos tradicionais 1 . A prática pedagógica em saúde mantémse baseada na idéia de que a apreensão do saber instituído sempre leva à aquisição de novos comportamentos e práticas, desconsiderando a história de vida do indivíduo, suas crenças, seus valores e sua subjetividade.

A descrição das práticas alimentares adotadas atualmente na adolescência tem correspondido a dietas ricas em gorduras, açúcares e sódio, com pequena participação de frutas e hortaliças $2,3,4,5$. Este quadro está relacionado à manifestação cada vez mais precoce de doenças crônicas entre os adolescentes, como a obesidade e o diabetes, o que envolve um grande impacto em saúde pública 6 . Nesse sentido, é fortemente estimulado o desenvolvimento de estratégias de intervenção nutricional, inseridas no campo da educação em saúde, como uma perspectiva para o controle do problema nessa fase da vida.

Em intervenções nutricionais, o foco central costuma ser a difusão de informações sobre os benefícios de determinados alimentos e nutrientes e os malefícios de outros 7. Acredita-se assim que o oferecimento de novas informações sobre alimentação e nutrição promove um aumento do conhecimento individual, o que, por sua vez, 
resultará em melhorias no comportamento alimentar. Contudo, o fracasso de intervenções do tipo conhecimento-atitude-comportamento é esperado, conforme relatado na literatura ${ }^{8}$.

Além disso, o referido modelo assume que o indivíduo, principalmente aquele com excesso de peso, apresenta um conhecimento deficiente sobre os aspectos nutricionais da dieta e as recomendações alimentares atuais, o que freqüentemente constitui um erro ${ }^{9}$. Apesar da crescente epidemia de obesidade em nível mundial, as noções básicas sobre o conceito de uma alimentação saudável são bem difundidas na população. Estudo realizado em 15 países da União Européia mostrou que a grande parte dos entrevistados apresentava definições satisfatórias de uma alimentação saudável ${ }^{10}$. Destaca-se ainda uma escassez de estudos semelhantes na adolescência.

Torna-se assim necessário reavaliar as intervenções nutricionais normalmente realizadas com adolescentes. O novo foco deve abranger o conhecimento do comportamento alimentar do indivíduo e de seu grupo social e a construção coletiva das estratégias adotadas. Intervenções pautadas nos conceitos, necessidades e crenças da população-alvo apresentam maior probabilidade de sucesso para a promoção de práticas alimentares saudáveis 11,12.

Acredita-se que a identificação dos principais fatores que modulam o comportamento alimentar é imprescindível para a adaptação de teorias que possam vir a fundamentar a intervenção nutricional 13 , bem como para o desenvolvimento de materiais educativos. Estes são componentes do processo de aprendizagem e facilitam a produção de conhecimento quando adotados de maneira participativa e interativa 14 .

A elaboração e o uso de materiais educativos em saúde deve se pautar no debate entre os significados e na valorização de experiências entre os responsáveis pelas intervenções e os integrantes do grupo-alvo. O diálogo crítico, que possibilite um processo comunicativo aberto, permite identificar interesses em comum entre os adolescentes e os responsáveis pela estratégia educativa, permitindo uma intervenção nutricional fundada na promoção da saúde e no alcance concreto dos objetivos esperados 14 .

O objetivo deste estudo foi avaliar as percepções sobre a dieta de adolescentes, identificando o conceito de alimentação saudável, as barreiras encontradas para adotá-la e as características para a elaboração de materiais educativos destinados à promoção de práticas alimentares adequadas.

\section{Materiais e métodos}

Neste estudo, optou-se pela técnica de grupo focal pelas vantagens oferecidas por este método quanto à formação de um ambiente propício para um debate informal entre os participantes, no qual são compartilhados sentimentos, entendimentos, experiências e conceitos. Trata-se de uma forma ideal para a exploração das atitudes e percepções dos adolescentes no ambiente social em que foram construídas 15 .

Para captação dos adolescentes participantes, foi selecionada uma escola por conveniência que autorizou a realização do estudo. O objetivo e a dinâmica do trabalho foram apresentados aos alunos de três turmas da $2^{\text {a }}$ série do Ensino Médio de uma escola da rede pública de ensino da Região Administrativa do Guará, no Distrito Federal, Brasil, em sala de aula, convidando-os a participar. Os critérios para participação no estudo foram: ter idade entre 10 e 19 anos, o que caracteriza a fase da adolescência, e estar matriculado na escola. Àqueles que manifestaram interesse, foi entregue o termo de consentimento livre e esclarecido para assinatura dos pais ou responsáveis. Após devolução deste assinado à diretoria da escola, foi agendada a realização dos grupos focais logo após a apresentação dos trabalhos finais das disciplinas, de modo a não interferir na participação do aluno nas atividades escolares. Os debates foram realizados em dezembro de 2007, em uma sala da própria escola na qual se encontravam os adolescentes.

As discussões dos grupos focais foram conduzidas por um facilitador, que seguiu um questionário semi-estruturado. Neste, constavam perguntas divididas em três blocos. O primeiro visava caracterizar a percepção dos adolescentes sobre sua alimentação e sua motivação para modificá-la, se considerado necessário. A sequência das perguntas baseou-se em uma adaptação do algoritmo proposto por Toral et al. ${ }^{16}$ para a classificação de estágios de mudança de comportamento. Contudo, o intuito foi de estimular a discussão sobre as próprias práticas alimentares, não para classificar os indivíduos em categorias de comportamento. Questionou-se, inicialmente, a respeito de quantos participantes acreditavam adotar uma alimentação saudável. Em caso de resposta afirmativa, perguntou-se há quanto tempo mantinham essa prática. Caso contrário, foi perguntado se os participantes pretendiam modificar sua alimentação e quando isso seria colocado em prática.

O segundo bloco de perguntas tinha como objetivo investigar o conceito dos adolescentes sobre uma alimentação saudável e as principais barreiras identificadas para sua adoção. Foi so- 
licitado aos participantes que descrevessem as características de uma dieta adequada e que listassem e justificassem os principais impedimentos para que os adolescentes não a adotem atualmente. As perguntas adotadas neste bloco foram "O que vocês entendem por 'alimentação saudável'?" " "Quais são as maiores dificuldades para se alimentar corretamente nos dias de hoje?".

O último bloco de perguntas apresentava uma situação fictícia para os adolescentes, nos quais eles eram responsáveis pelo desenvolvimento de materiais educativos impressos para a promoção de práticas alimentares saudáveis entre seus colegas. A pergunta-base deste bloco foi: "Como vocês acham que deveria ser um material educativo impresso para motivar seus colegas tanto a ler seu conteúdo, como a adotar de fato uma alimentação saudável no seu dia a dia?". Em seguida, a discussão foi conduzida para que fossem identificadas as características desses materiais quanto ao formato, apresentação, tamanho, informações contidas, periodicidade de distribuição e as estratégias para motivar os colegas a ler os impressos.

Com a autorização dos participantes, os debates foram gravados em meio digital e posteriormente transcritos para análise, sendo identificados os principais núcleos de sentido presentes nos discursos 17. A análise do material discursivo deu-se por meio de uma leitura sistemática flutuante de todo o material registrado, previamente digitado. Em seguida, agregaram-se os conteúdos discursivos semelhantes relacionados a cada um dos blocos de perguntas apresentados anteriormente. Este procedimento apoiou-se na técnica de conteúdo, que, segundo Bardin 17, caracteriza-se por ser um processo investigativo que tem por finalidade a descrição, objetiva, sistemática e quantitativa do conteúdo manifesto na comunicação. Para tanto se aplicou o recurso da análise categorial, por meio de delimitações de unidades de codificação, que a partir da totalidade do texto, verificou, com base em critérios de classificação, a freqüência, ou não, da presença de itens de sentido. Torna-se, assim, um método taxionômico que visa introduzir uma ordem, segundo certos critérios, em uma desordem aparente 18 .

Este estudo foi aprovado pelo Comitê de Ética em Pesquisa da Faculdade de Saúde Pública da Universidade de São Paulo.

\section{Resultados}

Foram realizados quatro grupos focais, sendo três com seis participantes e um com sete participantes. Do total de 25 adolescentes, 13 eram do sexo feminino (52\%). A média de idade foi de 17 anos e os debates tiveram uma duração em torno de 30 a 40 minutos.

\section{Percepção sobre sua alimentação e motivação para realizar alterações}

Inicialmente, ao questionar quantos adolescentes acreditavam que possuíam uma alimentação saudável, verificou-se que alguns participantes manifestavam sua indecisão quanto a esse critério, dizendo:

"Regular vale?”.

"Eu tento".

"Tipo assim, começa na primeira semana [a tentativa de adoção de uma alimentação saudável], depois volta tudo de novo".

Entre os adolescentes que afirmaram que tinham uma alimentação saudável há um tempo considerável, foi observado que a incorporação de práticas adequadas desde a infância era decorrente da influência dos pais:

"Desde que eu nasci, minha mãe pega no meu pé".

"A minha [dieta] sempre foi assim [saudável], meu pai e minha mãe sempre falaram”.

A maioria dos adolescentes que disse não ter uma alimentação saudável afirmou que gostaria de modificar sua dieta, mas não se sentia confiante para conduzir essa modificação naquele momento.

\section{Conceito de alimentação saudável e principais} barreiras para adotá-la

De forma geral, os adolescentes mostraram ter um conceito adequado sobre uma alimentação saudável, enfatizando a importância de critérios como o equilíbrio, a moderação, a variedade dos alimentos, o fracionamento da dieta e a participação dos nutrientes.

"É um balanceamento, eu acho, você não vai exagerar em um, nem em outro [alimento]”.

"É uma alimentação na medida, um prato que contenha todos os nutrientes que a pessoa precisa para seu corpo".

"Tem que ter um pouco de cada coisa, tem que ser variada, nada em excesso, na medida certa”.

"O ideal é comer pouco, mas muitas vezes ao dia e na hora certa também. A quantidade certa em cada hora".

"É nutriente. Proteínas, lipídios, carboidratos, vitaminas... tudo".

Algumas falas também destacaram a necessidade de ter uma participação reduzida de guloseimas, alimentos industrializados e fast-food.

"Precisa cortar as besteiras que eu como. Porque eu tenho uma alimentação saudável, só que 
chega fim de semana, de noite, é hambúrguer, é bomba, é lanche daqui e ali, nunca dá certo".

"Tem que ter salada, uma fruta depois do almoço, água, suco feito na hora, não de saquinho, não refrigerante...".

"Comidas rápidas geralmente não são saudáveis. Um pacote de biscoito, uma lasanha congelada, um hambúrguer.. não tem os nutrientes necessários para você".

As principais barreiras identificadas pelos adolescentes para adotar uma alimentação adequada foram: o sabor dos alimentos considerados saudáveis, a gula ou "tentação" e a praticidade dos alimentos pouco saudáveis.

“Ah, esse negócio [alimentação saudável] é ruim".

"As coisas que engordam são muito boas".

"Tipo, você pode escolher entre um suco e um refrigerante. Aí eu não consigo, eu compro o refrigerante. É mais gostoso, é viciante".

"As lanchonetes sempre tentam a gente. Você sente aquele cheirinho... Se eu sentir o cheiro, eu tenho que comer, não tem jeito".

"Tipo eu faço isso: passo ali, compro uma besteira e como. Prático e rápido. É mais cômodo para a gente".

Tanto o dinheiro como o tempo foram apresentados de forma contraditória: a falta e o excesso de ambos foram listados como barreiras para a adoção de uma alimentação saudável.

"Comer saudável é caro, mas depende do lugar. Se for de qualidade é caro".

"Às vezes, é o excesso de dinheiro que faz você comprar besteira".

"Com certeza comer um prato de salada num restaurante é muito mais barato do que você comer um sanduíche no McDonald's".

"Um sanduíche natural é oito Reais. Mas no McDonald's, custa oito Reais o sanduíche, com a batata frita e o refrigerante. Não tem como não dar preferência".

"Tem dia que não dá para voltar para casa. É sair da escola e já vai pro inglês. Eu almoço na escola, tem que engolir a comida".

"Quando a gente tem muito tempo para comer, a gente come muito. Mas quando a gente tem pouco, a alimentação fica desregulada. Tem dias que não sobra tempo para nada".

Outro aspecto que parece ser considerado tanto como barreira como facilitador da adoção de uma dieta adequada corresponde ao período de férias escolares.

"Eu acho que no período da escola você sente muito mais fome. Nas férias, você fica o dia todo na rua. Na escola, você vai pro intervalo, come um cachorro-quente, uma pizza...".

"Não, eu acho que no período da escola é muito mais fácil emagrecer. Se eu estou em casa, estou comendo. Eu vou lá na geladeira, pego uma coisa para comer...".

"Vou mudar minha alimentação depois das férias. Nas férias tem que comer besteira mesmo. Depois eu vou começar a correr, vou na academia...".

Foi observada uma dificuldade para modificar o consumo devido ao fato de as aquisições dos alimentos serem feitas pelos pais ou responsáveis. Por outro lado, algumas falas mostram influência positiva dos familiares sobre as práticas alimentares dos adolescentes.

"Na minha casa quem compra geralmente as coisas são meu pai e minha mãe. E aí eu tenho dificuldade de comprar as coisas que eu quero".

"Todo dia, antes de vir para a escola, minha mãe faz eu trazer uma maçã ou uma banana. Aí chego em casa, ela me 'bota' para comer outras frutas, todo dia".

Também se ressaltou a falta de opções de lanches saudáveis na escola.

"A escola influencia. Às vezes a gente come salgado, fritura [na lanchonete] de manhã. E a primeira alimentação que a gente tem é essa. Fritura de manhã não é muito bom, não".

\section{Desenvolvimento de materiais educativos de promoção de alimentação saudável}

Após a apresentação da situação hipotética em que os participantes seriam responsáveis pelo desenvolvimento de materiais educativos sobre alimentação saudável para seus colegas, foram investigadas inicialmente as possibilidades de formato. As opções mais mencionadas referiramse a revistas ou gibis.

"Revista todo adolescente gosta".

"Um gibi, uma historinha com desenhos bonitinhos".

"Ninguém vota no jornal. Da nossa idade, poucas pessoas lêem jornal".

"Panfleto não. Você pega um monte de papel ali fora, ninguém nem lê e joga fora. Ninguém nem liga. Tem que ser grande para a pessoa pegar e não jogar fora".

Todos afirmaram que seria imprescindível que o material fosse colorido, já que este em preto e branco não chamaria a atenção dos adolescentes. Quanto ao tamanho e extensão do conteúdo, destacou-se a importância de ser um material de poucas páginas. A periodicidade sugerida com maior freqüência foi quinzenal e mensal.

“Tem que ser algo que chame a atenção pela beleza. Algo colorido, com dobraduras, que atraisse o jovem".

"Não pode ter muita coisa escrita, não, se não o povo fica com preguiça de ler. Tem que pôr coisa que a pessoa vai ler e captar na hora". 
Os adolescentes enfatizaram a necessidade de apresentar mensagens que mostrassem os graves riscos de saúde decorrentes de uma alimentação inadequada. Os participantes afirmaram que a melhor estratégia para motivar os colegas a adotar uma dieta adequada seria "assustá-los", como mostram as seguintes falas.

“Eu 'botaria' medo na pessoa. Quanto mais medo, mais ela vai mudar".

"Você ia 'botar' a foto de uma pessoa super gorda. Aí a pessoa vai ler e falar: 'nossa, essa pessoa sofre disso, disso e disso. Eu não quero passar por isso'. A pessoa gorda tem vergonha de andar sem blusa, de ir à piscina...".

"Tem que ter uma mensagem-bomba, drástica. Tem que falar dos riscos, o que acontece com quem não se alimenta bem".

Além disso, vários participantes gostariam de incluir depoimentos de pessoas que superaram problemas de saúde ou melhoraram suas práticas alimentares, como uma "lição de vida". Foi sugerida a inclusão de informações de calorias de alimentos, principalmente em relação a alimentos comuns na sua alimentação, como cachorro-quente, refrigerante, chocolate e frituras. Também propuseram a inclusão de curiosidades sobre alimentos, destaque para as contribuições para a beleza, opções de substituição de alimentos e receitas saudáveis.

"Curiosidades sempre chamam a atenção. Tipo 'uma fruta tem o dobro de vitamina da outra"'.

"Poderia falar 'você troca um biscoito por uma maçã que eles têm a mesma quantidade de calorias, então é mais saudável"'.

"Receitas seriam legais, se fossem boas, atraentes. Sanduíche natural, torta de maçã, ou de cenoura, um doce de fruta. Que chame a atenção e seja fácil".

Destacou-se como estratégia para convencer os colegas a lerem o material e para comprovar que captaram os conceitos apresentados a inclusão de jogos, como caça-palavras e testes, ou a inclusão de cupons para a participação de sorteio de brindes, mediante o preenchimento de um questionário sobre o tema abordado no material.

"Poderia ter um questionário para preencher meio escondido, para ver se ela leu. Tipo, você tinha que responder alguma coisa que estava dentro daquele texto que a pessoa leu e ela tinha que ler muito para elaborar aquela resposta. As melhores respostas ganhariam alguma coisa".

"Acho que tinha que ter um sorteio de alguma coisa. Algo material mesmo. Sei lá, depois de seis meses, que concorresse a uma bicicleta, um $\mathrm{mp} 4$, um notebook...".

\section{Discussão}

A indecisão apresentada entre os adolescentes do estudo sobre a atual adoção ou não de uma dieta adequada pode ser atribuída a alguns fatores. Considerando que a dieta envolve a ingestão de centenas de alimentos e bebidas, a dúvida pode ter surgido ao ter que avaliar o conjunto das práticas alimentares, e não a pormenorização do consumo alimentar. Segundo Rodrigues \& Boog 19, o "comer certo" para o adolescente pressupõe a exclusão de todos aqueles produtos que compõem o grupo dos "maus", o que impede um balanceamento ao se fazer uma reflexão sobre a prática alimentar. Além disso, acreditase que nessa fase da vida os participantes já tenham incorporado o "desejo social" de se ter uma alimentação saudável, ou seja, sabem que o esperado seria afirmar que possuem dietas adequadas como forma de "não decepcionar" tanto o pesquisador como os colegas 20 .

Outra justificativa para que os adolescentes não tenham categorizado rapidamente sua própria alimentação como saudável ou não pode ser atribuída ao fato de que a população freqüentemente não dispõe de instrumentos suficientes para avaliar a própria dieta. Alguns estudos têm identificado que entre $40 \%$ a $70 \%$ da população afirmam não ser necessário alterar seu consumo alimentar porque já adotam uma dieta saudável 21,22,23. Porém, esse relato é contraditório frente ao crescente aumento da prevalência de doenças crônicas associadas às práticas alimentares cada vez mais destoantes do preconizado por guias alimentares em todo o mundo 24 .

Deve-se destacar a falta de confiança apresentada pelos adolescentes deste estudo para modificações concretas na alimentação num futuro próximo. Essa fase, que pode ser caracterizada como um estágio de "contemplação", abrange a identificação de diversas barreiras para alterar a prática alimentar, apesar do conhecimento dos possíveis benefícios que seriam decorrentes da mudança 25. Tal situação é confirmada com a extensa lista de dificuldades identificadas pelos participantes do estudo para a adoção de uma dieta adequada. Nesse sentido, intervenções nutricionais devem atuar de forma a motivar a auto-eficácia dos indivíduos e a habilitá-los para a superação das barreiras encontradas que os impedem de agir.

A apresentação de conceitos adequados referentes a uma dieta saudável pelos participantes pode representar que a divulgação das informações de alimentação e nutrição nos meios de comunicação tem sido adequada e efetiva no sentido de alcançar o público adolescente. Outros estudos também mostraram que tanto jovens 
como adultos têm uma noção adequada sobre as práticas alimentares recomendadas, normalmente enfatizando a participação de frutas e verduras, dos nutrientes e o equilíbrio entre os grupos de alimentos 10,26,27.

Isto pode ser atribuído à constante veiculação de assuntos relacionados à alimentação e nutrição na mídia. Uma limitação deste estudo corresponde à falta de investigação das principais fontes de informação adotadas pelos adolescentes. Contudo, Santos \& Barros Filho 28 identificaram que as principais fontes apontadas por universitários correspondiam às revistas, aos médicos e aos programas de televisão; já as fontes consideradas mais confiáveis foram os médicos e os nutricionistas e as menos confiáveis, os jornais e os programas de televisão.

As barreiras identificadas pelos participantes para adotar uma alimentação saudável são condizentes com as observações de outros estudos. O sabor e a praticidade dos alimentos considerados pouco saudáveis são freqüentemente citados entre as principais barreiras levantadas pelos jovens 27,29 . O fato de fast-foods e outros alimentos de baixa qualidade nutricional não exigirem habilidades culinárias ou simplesmente já estarem prontos para o consumo está relacionado também à outra barreira citada: a falta de tempo. Porém, estes são aspectos que podem ser trabalhados em intervenções nutricionais, enfatizando as opções de alimentos saudáveis e palatáveis em receitas de preparo rápido.

O caráter contraditório da família, em especial dos pais, que foi relatado pelos participantes, atuando tanto como facilitador e barreira para a adoção de práticas alimentares saudáveis também tem sido relatado em outros estudos. Segundo Gellar et al. 27 o tipo de alimentação disponível em casa, adquirida pelos familiares, foi citado como barreira para se ter uma alimentação saudável entre os adolescentes; contudo, a família foi citada como a principal influência em favor de uma alimentação saudável. Da mesma forma, adolescentes costarriquenhos também se sentem totalmente dependentes das decisões dos pais em relação a suas práticas alimentares 30 .

A contradição observada quanto ao papel da família pode ainda ser interpretada pela ótica dos ritos de passagem da puberdade, em que a criança abandona o mundo da infância e passa a ser um indivíduo pronto para assumir sua atuação como adulto na sociedade 31 . Nesse sentido, os participantes tenderiam a apresentar uma visão ainda dúbia frente à família: esta é tanto a fonte de sabedoria e acolhimento para a adoção de práticas alimentares saudáveis, como também, o elo com a infância distante, que é questionada, abandonada ou recusada pelo adolescente.
Assim como observado neste estudo, Bauer et al. ${ }^{26}$ e Monge-Rojas et al. 30 também identificaram que o acesso facilitado a alimentos de baixo valor nutricional e a qualidade da alimentação servida dentro do ambiente escolar foram citados como empecilhos para a adoção de uma alimentação saudável. No estudo de Gellar et al. 27,o ambiente escolar também foi descrito como o local de maior exposição a alimentos pouco saudáveis. O reconhecimento dessa situação e a necessidade de serem estabelecidas condições propícias em âmbito nacional para a adoção de práticas alimentares nas escolas culminou na publicação da Portaria Interministerial $n^{\circ}$. $1.010^{32}$, que instituiu diretrizes para a promoção da alimentação saudável em todas as escolas do país.

Considerando que a adoção de um estilo de vida saudável deve ocorrer desde a infância e a adolescência, compreender as percepções dos jovens sobre uma alimentação saudável é fundamental para o delineamento adequado de materiais educativos e intervenções nutricionais 27 . Além disso, tem-se observado visões diferentes sobre a saúde do adolescente entre os serviços de saúde voltados para este grupo populacional e os próprios adolescentes: enquanto estes apresentam uma atitude positiva em relação à saúde, a princípio não pensando em risco, os serviços insistem em vê-los como o próprio risco 33,34. Dessa forma, a situação apresentada aos adolescentes neste estudo para o desenvolvimento de materiais educativos incentivou uma atitude protagonista dos participantes no sentido de que eles seriam os responsáveis pela condução de uma intervenção nutricional.

Os participantes descreveram que o material educativo deveria ser apresentado no formato de revista ou gibi, entregue com freqüência quinzenal ou mensal, envolvendo atrativos visuais e uma linguagem simples e direta. Foi enfatizada a necessidade de inclusão de aspectos com os quais os adolescentes possam se identificar, como as possibilidades de substituição de alimentos que tradicionalmente fazem parte de suas dietas e a apresentação do material voltada para o jovem. Deve ser considerado que a mudança do comportamento alimentar do adolescente somente será alcançada quando este perceber seu sentido em sua história de vida, englobando o individual e o social, a emoção e a ação 19 .

A necessidade de inclusão de mensagens alarmantes e "assustadoras", mostrando os graves riscos à saúde atribuídos à adoção de uma alimentação inadequada, conforme levantado pelos adolescentes do estudo, é justificável nessa fase da vida. O senso de indestrutibilidade, a visão muito otimista e esperançosa sobre si 
próprios e a fraca noção de determinadas práticas sobre a saúde futura na adolescência podem determinar que a nutrição seja um tema de pouca preocupação nessa fase da vida 28,33 , o que justificaria a necessidade levantada nos debates de ter que "passar medo" nas mensagens de alimentação e nutrição para chamar a atenção dos colegas. Intervenções nutricionais voltadas para adolescentes não podem focar os possíveis prejuízos à qualidade de vida que poderão ser observados em algumas décadas; devem enfatizar os aspectos de saúde que são considerados relevantes nessa fase da vida, como as associações entre o consumo alimentar e o desempenho escolar, o sucesso nos esportes e a aparência física.

Segundo Cromack et al. ${ }^{34}$, a alimentação foi listada como um elemento central das representações sociais de saúde por adolescentes de escolas públicas do Rio de Janeiro, demonstrando uma preocupação positiva do adolescente em relação a sua saúde. Nesse sentido, outra possibilidade para interpretar a necessidade de se adotar mensagens alarmantes nos materiais educativos pode ser o fato de que a alimentação é algo que está sob o controle do adolescente e que ele pode tratar de seu corpo por meio de uma dieta adequada. Haveria, portanto, a necessidade de enfatizar a responsabilidade do jovem com seu corpo e sua saúde, alertando-o para a realização de mudanças imediatas e a prevenção de doenças. Esta responsabilidade é um fator característico da maturidade, a qual o adolescente entra em contato nesta fase da vida e é constantemente cobrado em seu cotidiano, como um passaporte para o mundo adulto 31 .

Contudo, cabe destacar a conduta ética essencial para o desenvolvimento dos materiais educativos, principalmente no que tange à abordagem da obesidade. Apesar dos participantes terem sugerido a veiculação de imagens de pessoas obesas como meio de atrair a atenção dos colegas para um grave problema de saúde, a exposição de imagens do tipo pode estimular o preconceito contra pessoas portadoras de doenças crônicas não-transmissíveis. A redução da obesidade a uma questão física restringe inclusive as possibilidades terapêuticas em nutrição, e ainda reforça uma concepção dicotômica de corpo separado da mente, ao contrário de uma visão integral indispensável para uma conduta ética frente ao problema 35 .

Destacou-se ainda, pelas falas dos adolescentes relativas à elaboração dos materiais educativos, a importância de se incluir um caráter lúdico às informações transmitidas, incluindo histórias em quadrinhos e jogos como estratégias de veiculação das mensagens de alimentação e nutrição.
Vale ressaltar que a análise desenvolvida neste estudo remete a uma realidade vivencial dos jovens, por meio de seus discursos, o que não obrigatoriamente revela uma verdade única. São falas "ilusórias, contraditórias e verdadeiras”, tidas como matéria-prima para a análise do social 33 . Os resultados obtidos informam acerca do momento e da capacidade avaliativa dos adolescentes em relação à alimentação saudável, por meio do exercício de suas funções cognitivas e afetivas. Para Rocha \& Deusdará 18, uma característica das pesquisas com abordagem qualitativa corresponde à sua função interpretativa, atingindo uma profundidade, levantando os "véus" que encobrem uma dada realidade, ultrapassando o plano das aparências e desvelando o conteúdo subjacente. Sendo assim, foi possível, por meio do material discursivo obtido, acessar outro espaço, o das condições sociais e psicológicas em que o jovem está inserido frente à questão da alimentação saudável.

Além disso, é necessário considerar que o sentido dado à alimentação vai além das funções nutricionais e biológicas. A alimentação humana envolve aspectos psicológicos, fisiológicos e sócio-culturais, classificando-se como um fenômeno de grande complexidade 36,37. Para Mintz 38, o comportamento relativo à comida relaciona-se diretamente ao sentido de nós mesmos e da própria identidade social. Desde cedo, a criança é envolvida em uma série de rituais que culminam com a internalização de um padrão alimentar. Este processo é acompanhado e estimulado por adultos afetivamente poderosos, o que confere ao comportamento alimentar um poder sentimental duradouro, o qual, por sua vez, se estende para as outras fases do desenvolvimento humano, incluindo a adolescência. Os jovens expressaram em seus discursos uma gama de valores, crenças e opiniões, calcados em um aprendizado familiar e social. Dessa forma, pode-se inferir que a escolha de um dado alimento em uma dada circunstância está repleta de significados, desejos, valores, atitudes e símbolos que repousam em uma esfera das representações sociais, as quais podem não ter sido contempladas em sua totalidade neste estudo.

\section{Conclusão}

Os jovens demonstraram conhecimento adequado sobre o padrão de uma alimentação saudável e identificaram barreiras focadas nas características dos alimentos, em aspectos individuais e sociais. Os achados deste estudo sugerem que o foco das intervenções nutricionais tradicionais, voltadas para o fornecimento de informações 
básicas sobre o conceito de uma alimentação saudável, deve ser profundamente modificado. É necessário prover o adolescente de meios para avaliar sua própria dieta e de estratégias para superar as barreiras encontradas para a adoção de práticas alimentares adequadas, estimulando, por exemplo, o contato com alimentos saudáveis de preparo rápido e sabor agradável. A inclusão da família na intervenção nutricional também é altamente recomendada, por ser considerada uma influência tanto positiva como negativa para a adoção de uma alimentação saudável.

\section{Resumo}

Este estudo visou avaliar percepções, barreiras e características de materiais educativos de promoção de alimentação saudável descritas por adolescentes. Realizaram-se quatro grupos focais com 25 adolescentes com perguntas sobre: percepção e motivação para modificar a dieta; conceito de alimentação saudável e barreiras para sua adoção; e características de impressos para a promoção de práticas alimentares saudáveis. Observou-se uma freqüente indecisão quanto a classificar a dieta como saudável. Os adolescentes referiram não se sentir confiantes para modificar a dieta, mas relataram conceitos adequados sobre alimentação saudável. As principais barreiras citadas foram focadas em aspectos pessoais e sociais, como: a tentação, o sabor dos alimentos, a influência dos pais e a falta de tempo e de opções de lanches saudáveis na escola. Para os jovens, materiais educativos de promoção de alimentação saudável devem reforçar seus benefícios imediatos e destacar mensagens alarmantes sobre os riscos à saúde advindos de uma alimentação inadequada.

Comportamento Alimentar; Saúde do Adolescente; Promoção da Saúde

\section{Colaboradores}

N. Toral concebeu o presente estudo, realizou o trabalho de campo, interpretou os dados e trabalhou na redação do artigo. M. A. Conti atuou na revisão crítica da versão final do manuscrito. B. Slater concebeu o presente estudo e atuou revisão crítica da versão final do manuscrito.
Em relação ao desenvolvimento de materiais educativos direcionados para a promoção de uma alimentação saudável, este estudo possibilitou o conhecimento de características específicas desejadas pelos adolescentes, que podem contribuir para a maior adesão dos mesmos à ação educativa, desde que seja incluído o caráter lúdico ao serem repassadas as informações e os critérios éticos na abordagem sobre o surgimento de doenças crônicas.

\section{Referências}

1. Gazzinelli MF, Gazzinelli A, Reis DC, Penna CMM. Educação em saúde: conhecimentos, representações sociais e experiências da doença. Cad Saúde Pública 2005; 21:200-6.

2. Schmidt M, Affenito SG, Striegel-Moore R, Khoury PR, Barton B, Crawford P, et al. Fast-food intake and diet quality in black and white girls. Arch Pediatr Adolesc Med 2005; 159:626-31.

3. Aranceta-Bartrina J, Serra-Majem L, Pérez-Rodrigo C, Ribas-Barba L, Delgado-Rubio A. Nutrition risk in the child and adolescent population of the Basque country: the enKid Study. Br J Nutr 2006; 96 Suppl 1:S58-66.

4. Carmo MB, Toral N, Silva MV, Slater B. Consumo de doces, refrigerantes e bebidas com adição de açúcar entre adolescentes da rede pública de ensino de Piracicaba, São Paulo. Rev Bras Epidemiol 2006; 9:121-30.

5. Toral N, Slater B, Silva MV. Consumo alimentar e excesso de peso de adolescentes de Piracicaba, São Paulo. Rev Nutr 2007; 20:449-59.

6. Cook S, Weitzman M, Auinger P, Nguyen M, Dietz WH. Prevalence of a metabolic syndrome phenotype in adolescents. Arch Pediatr Adolesc Med 2003;157:821-7.

7. Castro IRR, Souza TSN, Maldonado LA, Caniné ES, Rotenberg S, Gugelmin SA. A culinária na promoção da alimentação saudável: delineamento e experimentação de método educativo dirigido a adolescentes e a profissionais das redes de saúde e de educação. Rev Nutr 2007; 20:571-88. 
8. Kristal AR, Bowen DJ, Curry SJ, Shattuck AL, Henry HJ. Nutrition knowledge, attitudes and perceived norms as correlates of selecting low-fat diets. Health Educ Res 1990; 5:467-77.

9. O'Brien G, Davies M. Nutrition knowledge and body mass index. Health Educ Res 2007; 22:571-5.

10. Margetts BM, Martinez JA, Saba A, Holm L, Kearney M, Moles A. Definitions of "healthy" eating: a pan-EU survey of consumer attitudes to food, nutrition and health. Eur J Clin Nutr 1997; 51 Suppl 2: S23-9.

11. Ni Mhurchu C, Margetts BM, Speller VM. Applying the stages-of-change model to dietary change. Nutr Rev 1997; 55(1 Pt 1):10-6.

12. Brug J, Steenhuis I, van Assema P, Vries H. The impact of a computer-tailored nutrition intervention. Prev Med 1996; 25:236-42.

13. Assis MAA, Nahas MV. Aspectos motivacionais em programas de mudança de comportamento alimentar. Rev Nutr 1999; 12:33-41.

14. Kelly-Santos A, Rozemberg B. Estudo de recepção de impressos por trabalhadores da construção civil: um debate das relações entre saúde e trabalho. Cad Saúde Pública 2006; 22:975-85.

15. Stevenson C, Doherty G, Barnett J, Muldoon OT, Trew K. Adolescents' views of food and eating: identifying barriers to healthy eating. J Adolesc 2007; 30:417-34.

16. Toral N, Slater B, Cintra IP, Fisberg M. Avaliação do comportamento alimentar de adolescentes em relação ao consumo de frutas e verduras. Rev Nutr 2006; 19:331-40.

17. Bardin L. Análise de conteúdo. Lisboa: Edições 70; 1995.

18. Rocha D, Deusdará B. Análise de conteúdo e análise do discurso: o lingüístico e seu entorno. DELTA: Documentação de Estudos em Lingüística Teórica e Aplicada 2006; 22:29-52.

19. Rodrigues EM, Boog MCF. Problematização como estratégia de educação nutricional com adolescentes obesos. Cad Saúde Pública 2006; 22:923-31.

20. Steptoe A, Wijetunge S, Doherty S, Wardle J. Stages of change for dietary fat reduction: associations with food intake, decisional balance and motives for food choice. Health Educ J 1996; 55:108-22.

21. Reid DJ, Conrad SA, Hendricks SM. Tracking nutrition trends, 1989-1994: an update on Canadians' attitudes, knowledge and reported actions. Can J Public Health 1996; 87:113-8.

22. Kearney M, Gibney MJ, Martinez JA, Almeida MDV, Friebe D, Zunft HJF, et al. Perceived need to alter eating habits among representative samples of adults from all member states of the European Union. Eur J Clin Nutr 1997; 51 Suppl 2:S30-5.

23. Biloukha O, Utermohlen V. Healthy eating in Ukraine: attitudes, barriers and information sources. Public Health Nutr 2001; 4:207-15.
24. Popkin BM. The nutrition transition and obesity in the developing world. J Nutr 2001; 131:871S-3S.

25. Prochaska JO, Redding CA, Evers KE. The transtheoretical model and stages of change. In: Glanz K, Lewis FM, Rimer BK. editors. Health behavior and health education: theory, research, and practice. $2^{\text {nd }}$ Ed. San Francisco: Jossey-Bass; 1996. p. 60-84.

26. Bauer KW, Yang YW, Austin SB. How can we stay healthy when you're throwing all of this in front of us? Health Educ Behav 2004; 31:34-46.

27. Gellar LA, Schrader K, Nansel TR. Healthy eating practices: perceptions, facilitators, and barriers among youth with diabetes. Diabetes Educ 2007; 33:671-9.

28. Santos KMO, Barros Filho AA. Fontes de informação sobre nutrição e saúde utilizadas por estudantes de uma universidade privada de São Paulo. Rev Nutr 2002; 15:201-10.

29. Neumark-Sztainer D, Story M, Perry C, Casey MA. Factors influencing food choices of adolescents: Findings from focus-group discussions with adolescents. J Am Diet Assoc 1999; 99:929-34.

30. Monge-Rojas R, Garita C, Sánchez M, Muñoz L. Barriers and motivators for healthful eating as perceived by rural and urban Costa Rican adolescents. J Nutr Educ Behav 2005; 37:33-40.

31. Brêtas JRS, Moreno RS, Eugenio DS, Sala DCP, Vieira TF, Bruno PR. Os rituais de passagem segundo adolescentes. Acta Paul Enferm 2008; 21:404-11.

32. Brasil. Portaria Interministerial $n^{\circ} .1 .010$, de 8 de maio de 2006. Institui as diretrizes para a Promoção da Alimentação Saudável nas Escolas de educação infantil, fundamental e nível médio das redes públicas e privadas, em âmbito nacional. Diário Oficial da União 2006; 9 jun.

33. Assis SG, Avanci JQ, Silva CMFP, Malaquias JV, Santos NC, Oliveira RVC. A representação social do ser adolescente: um passo decisivo na promoção da saúde. Ciênc Saúde Coletiva 2003; 8:669-79.

34. Cromack LMF, Bursztyn I, Tura LFR. O olhar do adolescente sobre saúde: um estudo de representações sociais. Ciênc Saúde Coletiva 2009; 14: 627-34.

35. Carvalho MC, Martins A. A obesidade como objeto complexo: uma abordagem filosófico-conceitual. Ciênc Saúde Coletiva 2004; 9:1003-12.

36. Poulain JP, Proença RPC. Reflexões metodológicas para o estudo das práticas alimentares. Rev Nutr 2003; 16:365-86.

37. Toral N, Slater B. Abordagem do modelo transteórico no comportamento alimentar. Ciênc Saúde Coletiva 2007; 12:1641-50.

38. Mintz SW. Comida e antropologia: uma breve revisão. Rev Bras Ciênc Soc 2001; 16:31-42.

Recebido em 26/Dez/2008

Versão final reapresentada em 04/Jul/2009

Aprovado em 03/Ago/2009 